(1)

CrossMark

\title{
Pulmonary complications of tyrosine kinase inhibitors in myeloproliferative disorders
}

\author{
Manuel J. Richter, Athiththan Yogeswaran and Khodr Tello
}

Affiliation: University of Giessen and Marburg Lung Center (UGMLC), member of the German Center for Lung Research (DZL) and of the Excellence Cluster Cardio-Pulmonary Institute (CPI), Giessen, Germany.

Correspondence: Manuel J. Richter, Pulmonary Hypertension Division, Medical Clinic II, University Hospital Giessen and Marburg GmbH, Klinikstrasse 36, 35392 Giessen, Germany. E-mail: manuel.richterdinnere.med. uni-giessen.de

@ERSpublications

The pulmonary physician must be aware of pulmonary toxicities if patients are treated with tyrosine kinase inhibitors. The compounds have different therapeutic targets and are associated to different extents with pulmonary complications. https://bit.ly/3gXUF8h

Cite this article as: Richter MJ, Yogeswaran A, Tello K. Pulmonary complications of tyrosine kinase inhibitors in myeloproliferative disorders. Eur Respir J 2020; 56: 2002653 [https://doi.org/10.1183/ 13993003.02653-2020].

Life has changed for patients with chronic myeloid leukaemia (CML) since the introduction of breakpoint cluster region-Abelson (Bcr-Abl) tyrosine kinase inhibitors (TKIs) in the late 1990s. Before the era of the TKIs began, the 5-year overall survival rates for patients with CML were approximately 28-66\%, depending on risk group, chemotherapy regimen and interferon use [1]. In 1996, the first oral TKI was investigated in pre-clinical studies and showed an astonishing reduction of tumour cell formation [2]. This TKI, later named imatinib, was the first to gain US and EU approval for CML in 2001 [3-5] and dramatically increased long-term survival rates to $76-94 \%$ at 6 years, depending on risk group [6]. Since then, various generations of Bcr-Abl TKIs have been developed, which induce even higher and faster rates of complete cytogenetic response than first-generation TKIs. To date, Bcr-Abl TKIs provide the basis for successful treatment of the underlying myeloproliferative disease [7].

However, this treatment class is not without toxicity. In the early years of development, the side-effect profile of the first-generation TKIs was considered rather benign, with vomiting, diarrhoea, anaemia and neutropenia observed at the highest dose levels in pre-clinical studies of imatinib [8] and minimal adverse events (most commonly nausea, myalgias, oedema and diarrhoea) reported in a pivotal clinical trial [3]. However, from 2007 onwards it became evident from case reports and retrospective registry analysis that Bcr-Abl TKIs exhibit cardiac [9] and predominately clinically relevant pulmonary toxicities [10-12], independent of the pulmonary complications associated with leukaemia per se [13].

In the present issue of the European Respiratory Journal, WEATHERALD et al. [14] comprehensively review the pulmonary complications of TKIs. They summarise key pathophysiological mechanisms and conclude that endothelial dysfunction, direct cell toxicity, enhanced cellular levels of reactive oxygen species, and/or inflammatory events contribute to the occurrence of pulmonary complications [14, 15]. Interestingly, besides sharing the major target of the Bcr-Abl oncogene, members of the presented TKI family have substantial differences in other molecular targets and occurrence of pulmonary complications. 


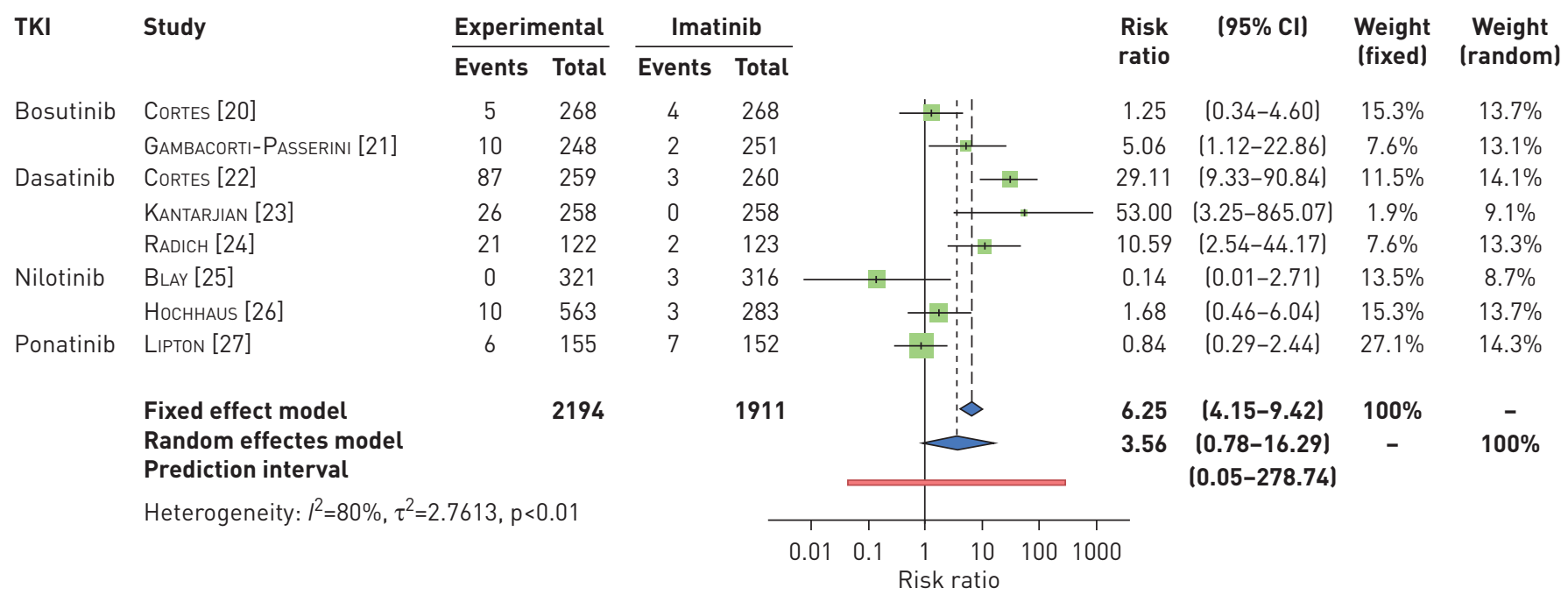

FIGURE 1 Forest plot of the risk ratio of pulmonary complications in patients receiving new-generation Bcr-Abl tyrosine kinase inhibitors (TKIs) (experimental) versus imatinib. A PubMed search for the terms imatinib, nilotinib, sorafenib, bosutinib, ponatinib and clinical trials (date range: January 2010 to June 2020) yielded 191 results, from which we selected 19 randomised, phase 3 trials. Of those, 11 studies were excluded (dose escalation and long-term extension studies, and studies lacking an imatinib control group or not reporting pulmonary adverse events). From the remaining eight studies, pulmonary complications (pleural effusion, pulmonary oedema, pulmonary hypertension and interstitial lung disease/ lung fibrosis) of any severity were pooled. Risk ratios and $95 \%$ confidence intervals were calculated using the Mantel-Haenszel method with continuity correction in R version 4.0.0 (The R Foundation, Vienna, Austria). Limitations: we did not have access to source data from the trials. In particular, a relevant number of studies only reported events occurring in $\geqslant 10 \%$ of patients.

This diversity of the Bcr-Abl TKI family has implications not only for the treatment of myeloproliferative disorders but also for investigations in other indications.

In 2005 (a little while before awareness of pulmonary complications began to grow), emerging pre-clinical and case report data suggested that the very first TKI imatinib might even have beneficial effects on the pulmonary vasculature $[16,17]$. The pre-clinical findings in particular were considered very promising at the time: imatinib was the first agent of this class to show the ability to reverse experimentally induced pulmonary hypertension $(\mathrm{PH})$ by exerting anti-proliferative and pro-apoptotic effects in the pulmonary vasculature [17]. In a clinical trial including patients with pulmonary arterial hypertension (PAH), imatinib improved haemodynamics and exercise capacity $[18,19]$. However, the study design and outcome and interpretation of the results were the subject of ongoing debate. Approval of imatinib for PAH was not sought, owing to the occurrence of serious non-pulmonary adverse events (including subdural haematoma in patients receiving anticoagulation $[18,19])$.

Nevertheless, as highlighted by the review of WEATHERALD et al. [14], imatinib and newer members of the TKI family such as nilotinib, bosutinib, ponatinib and, especially, dasatinib were found to be associated with a high incidence of pulmonary complications, such as pleural effusion and even induced $\mathrm{PH}$ or interstitial lung disease in individual cases. This prompts the question: do all Bcr-Abl TKIs lead to similar pulmonary complications or might imatinib show a more favourable profile? To address this question, we performed a systematic meta-analysis of the new-generation Bcr-Abl TKIs (included in the review by WeAtherald et al. [14]) versus imatinib. We included data from eight randomised, controlled, phase 3 clinical trials (seven in patients with CML, and one in patients with metastatic gastrointestinal stromal tumours) with imatinib as the control [20-27]. Our data showed that the risk ratio of all-grade pulmonary complications with new-generation TKIs compared with imatinib was 3.56 (95\% CI 0.78-16.29) overall, albeit with a significant degree of heterogeneity $\left(\mathrm{I}^{2}=80 \%\right)$. The risk ratio varied depending on the new-generation TKI, and was highest for dasatinib (figure 1).

Obviously, the risk profile of TKIs is of major importance. Few studies have systematically documented pulmonary complications, but the few existing data reveal a more favourable risk profile for imatinib, especially in comparison with dasatinib. As nicely described by WEATHERALD et al. [14], this might be attributable to differences in the target phosphokinome. Bosutinib, ponatinib and dasatinib have partially overlapping profiles and, in contrast to imatinib, target Src kinases and protein kinase families linked with endothelial function and mitochondrial reactive oxygen species production, which may underlie the observed pulmonary complications. The existing data do not justify condemning TKIs with an increased risk of pulmonary adverse events, but they do emphasise the need for frequent follow-ups, awareness and management after initiation of TKI therapy. 
That being said, the beneficial effects of imatinib on pulmonary haemodynamics in patients with PAH [18] may still merit further investigation. A more careful selection of patients, excluding for instance patients receiving anticoagulation and introducing mandatory imaging of the brain before therapy, might even pave the way for imatinib to become indicated in $\mathrm{PAH}$. As disease-modifying drugs in $\mathrm{PH}$ are rare, trials using anti-proliferative drugs are urgently needed. With knowledge of the adverse event profile and careful monitoring, studies using repurposed imatinib (www.clinicaltrials.gov NCT04416750) or inhaled modifications [28] in $\mathrm{PH}$ are feasible.

We congratulate WeATHERALD et al. [14] for their comprehensive review and for bringing the pulmonary complications of Bcr-Abl TKIs to the front desk of the European Respiratory Journal. The pulmonary physician has to be aware of pulmonary toxicities if patients are treated with Bcr-Abl TKIs, because despite being a united TKI family, the compounds have different therapeutic targets and are associated to different extents with pulmonary complications.

Acknowledgements: Editorial assistance was provided by Claire Mulligan (Beacon Medical Communications Ltd, Brighton, UK), funded by the University of Giessen.

Conflict of interest: M.J. Richter reports grants from the Excellence Cluster Cardio-Pulmonary System (ECCPS) and the Collaborative Research Center (SFB) 1213 - Pulmonary Hypertension and Cor Pulmonale, grant number SFB1213/1, project B08 and A08 (German Research Foundation, Bonn, Germany), non-financial (editorial) support from University of Giessen, during the conduct of the study; grants from United Therapeutics, grants and personal fees for consultancy and lectures from Bayer, personal fees for lectures from Actelion, outside the submitted work. A. Yogeswaran has nothing to disclose. K. Tello reports grants from the Excellence Cluster Cardio-Pulmonary System (ECCPS) and the Collaborative Research Center (SFB) 1213 - Pulmonary Hypertension and Cor Pulmonale, grant number SFB1213/1, project B08 and A08 (German Research Foundation, Bonn, Germany), non-financial (editorial) support from University of Giessen, during the conduct of the study; personal fees for lectures from Actelion and Bayer, outside the submitted work.

\section{References}

1 Allan NC, Richards SM, Shepherd PC. UK Medical Research Council randomised, multicentre trial of interferon-alpha $\mathrm{n} 1$ for chronic myeloid leukaemia: improved survival irrespective of cytogenetic response. The UK Medical Research Council's Working Parties for Therapeutic Trials in Adult Leukaemia. Lancet 1995; 345: 1392-1397.

2 Druker BJ, Tamura S, Buchdunger E, et al. Effects of a selective inhibitor of the Abl tyrosine kinase on the growth of Bcr-Abl positive cells. Nat Med 1996; 2: 561-566.

3 Druker BJ, Talpaz M, Resta DJ, et al. Efficacy and safety of a specific inhibitor of the BCR-ABL tyrosine kinase in chronic myeloid leukemia. N Engl J Med 2001; 344: 1031-1037.

4 European Medicines Agency. Glivec. www.ema.europa.eu/en/medicines/human/EPAR/glivec Date last updated: 12 February 2020. Date last accessed: 30 June 2020.

5 US Food and Drug Administration. Drug approval package - Gleevec (imatinib mesylate) capsules. www. accessdata.fda.gov/drugsatfda_docs/nda/2001/21335_Gleevec.cfm Date last updated: 17 October 2001. Date last accessed: 30 June 2020.

6 Baccarani M, Cortes J, Pane F, et al. Chronic myeloid leukemia: an update of concepts and management recommendations of European LeukemiaNet. J Clin Oncol 2009; 27: 6041-6051.

7 Pottier C, Fresnais M, Gilon M, et al. Tyrosine kinase inhibitors in cancer: breakthrough and challenges of targeted therapy. Cancers (Basel) 2020; 12: 731.

8 Druker BJ, Lydon NB. Lessons learned from the development of an Abl tyrosine kinase inhibitor for chronic myelogenous leukemia. J Clin Invest 2000; 105: 3-7.

9 Atallah E, Durand JB, Kantarjian H, et al. Congestive heart failure is a rare event in patients receiving imatinib therapy. Blood 2007; 110: 1233-1237.

10 Montani D, Bergot E, Gunther S, et al. Pulmonary arterial hypertension in patients treated by dasatinib. Circulation 2012; 125: 2128-2137.

11 Bergeron A, Rea D, Levy V, et al. Lung abnormalities after dasatinib treatment for chronic myeloid leukemia: a case series. Am J Respir Crit Care Med 2007; 176: 814-818.

12 Yo SW, Thenganatt J, Lipton J, et al. EXPRESS: incident pulmonary arterial hypertension associated with bosutinib. Pulm Cir 2020.

13 Hildebrand FL Jr, Rosenow EC 3rd, Habermann TM, et al. Pulmonary complications of leukemia. Chest 1990; 98: 1233-1239.

14 Weatherald J, Bondeelle L, Chaumais M-C, et al. Pulmonary complications of Bcr-Abl tyrosine kinase inhibitors. Eur Respir J 2020; 56: 2000279.

15 Phan C, Jutant EM, Tu L, et al. Dasatinib increases endothelial permeability leading to pleural effusion. Eur Respir J 2018; 51: 1701096.

16 Ghofrani HA, Seeger W, Grimminger F. Imatinib for the treatment of pulmonary arterial hypertension. $N$ Engl J Med 2005; 353: 1412-1413.

17 Schermuly RT, Dony E, Ghofrani HA, et al. Reversal of experimental pulmonary hypertension by PDGF inhibition. J Clin Invest 2005; 115: 2811-2821.

18 Hoeper MM, Barst RJ, Bourge RC, et al. Imatinib mesylate as add-on therapy for pulmonary arterial hypertension: results of the randomized IMPRES study. Circulation 2013; 127: 1128-1138.

19 Frost AE, Barst RJ, Hoeper MM, et al. Long-term safety and efficacy of imatinib in pulmonary arterial hypertension. J Heart Lung Transplant 2015; 34: 1366-1375. 
20 Cortes JE, Gambacorti-Passerini C, Deininger MW, et al. Bosutinib versus imatinib for newly diagnosed chronic myeloid leukemia: results from the randomized BFORE Trial. J Clin Oncol 2018; 36: 231-237.

21 Gambacorti-Passerini C, Cortes JE, Lipton JH, et al. Safety of bosutinib versus imatinib in the phase 3 BELA trial in newly diagnosed chronic phase chronic myeloid leukemia. Am J Hematol 2014; 89: 947-953.

22 Cortes JE, Saglio G, Kantarjian HM, et al. Final 5-year study results of DASISION: the dasatinib versus imatinib study in treatment-naive chronic myeloid leukemia patients trial. J Clin Oncol 2016; 34: 2333-2340.

23 Kantarjian H, Shah NP, Hochhaus A, et al. Dasatinib versus imatinib in newly diagnosed chronic-phase chronic myeloid leukemia. N Engl J Med 2010; 362: 2260-2270.

24 Radich JP, Kopecky KJ, Appelbaum FR, et al. A randomized trial of dasatinib $100 \mathrm{mg}$ versus imatinib $400 \mathrm{mg}$ in newly diagnosed chronic-phase chronic myeloid leukemia. Blood 2012; 120: 3898-3905.

25 Blay JY, Shen L, Kang YK, et al. Nilotinib versus imatinib as first-line therapy for patients with unresectable or metastatic gastrointestinal stromal tumours (ENESTg1): a randomised phase 3 trial. Lancet Oncol 2015; 16: 550-560.

26 Hochhaus A, Saglio G, Hughes TP, et al. Long-term benefits and risks of frontline nilotinib vs imatinib for chronic myeloid leukemia in chronic phase: 5-year update of the randomized ENESTnd trial. Leukemia 2016; 30: 1044-1054.

27 Lipton JH, Chuah C, Guerci-Bresler A, et al. Ponatinib versus imatinib for newly diagnosed chronic myeloid leukaemia: an international, randomised, open-label, phase 3 trial. Lancet Oncol 2016; 17: 612-621.

28 Pitsiou G, Zarogoulidis P, Petridis D, et al. Inhaled tyrosine kinase inhibitors for pulmonary hypertension: a possible future treatment. Drug Des Devel Ther 2014; 8: 1753-1763. 